\title{
Comparative Genetic Analysis of Magnaporthe oryzae Isolates Causing Gray Leaf Spot of Perennial Ryegrass Turf in the United States and Japan
}

\author{
Y. Tosa, Visiting Scholar, W. Uddin, Associate Professor, G. Viji, Postdoctoral Associate, and S. Kang, Associate \\ Professor, Department of Plant Pathology, The Pennsylvania State University, University Park 16802; and \\ S. Mayama, Professor, Faculty of Agriculture, Kobe University, Nada, Kobe 657-8501, Japan
}

\begin{abstract}
Tosa, Y., Uddin, W., Viji, G., Kang, S., and Mayama, S. 2007. Comparative genetic analysis of Magnaporthe oryzae isolates causing gray leaf spot of perennial ryegrass turf in the United States and Japan. Plant Dis. 91:517-524.

Gray leaf spot caused by Magnaporthe oryzae is a serious disease of perennial ryegrass (Lolium perenne) turf in golf course fairways in the United States and Japan. Genetic relationships among $M$. oryzae isolates from perennial ryegrass (prg) isolates within and between the two countries were examined using the repetitive DNA elements MGR586, Pot2, and MAGGY as DNA fingerprinting probes. In all, 82 isolates of $M$. oryzae, including 57 prg isolates from the United States collected from 1995 to 2001, 1 annual ryegrass (Lolium multiflorum) isolate from the United States collected in 1972, and 24 prg isolates from Japan collected from 1996 to 1999 were analyzed in this study. Hybridization with the MGR586 probe resulted in approximately 30 DNA fragments in 75 isolates (designated major MGR586 group) and less than 15 fragments in the remaining 7 isolates (designated minor MGR586 group). Both groups were represented among the 24 isolates from Japan. All isolates from the United States, with the exception of one isolate from Maryland, belonged to the major MGR586 group. Some isolates from Japan exhibited MGR586 fingerprints that were identical to several isolates collected in Pennsylvania. Similarly, fingerprinting analysis with the Pot 2 probe also indicated the presence of two distinct groups: isolates in the major MGR586 group showed fingerprinting profiles comprising 20 to 25 bands, whereas the isolates in the minor MGR586 group had less than 10 fragments. When MAGGY was used as a probe, two distinct fingerprint types, one exhibiting more than 30 hybridizing bands (type I) and the other with only 2 to 4 bands (type II), were identified. Although isolates of both types were present in the major MGR586 group, only the type II isolates were identified in the minor MGR586 group. The parsimony tree obtained from combined MGR586 and Pot 2 data showed that 71 of the 82 isolates belonged to a single lineage, 5 isolates formed four different lineages, and the remaining 6 (from Japan) formed a separate lineage. This study indicates that the predominant groups of $M$. oryzae associated with the recent outbreaks of gray leaf spot in Japan and the United States belong to the same genetic lineage.
\end{abstract}

Additional keywords: genetic diversity, Pyricularia grisea, Pyricularia oryzae, turfgrass

Gray leaf spot of perennial ryegrass ( $\mathrm{Lo}$ lium perenne L.) recently has emerged as a serious problem in the maintenance of perennial ryegrass (prg) for golf course fairways in the United States. Outbreaks of gray leaf spot on annual ryegrass ( $L$. multiflorum Lam.) grown for forage in the southern United States first were reported in the early 1970s in Louisiana and Mississippi $(1,2)$. In 1991, the disease first was reported on prg turf in golf course fairways in Pennsylvania (15). Severe outbreaks of the disease causing more than $98 \%$ loss of turf were reported in 1998 (27) and, since then, outbreaks of gray leaf spot have occurred every 2 to 3 years, resulting in seri-

Corresponding author: W. Uddin

E-mail: wxu2@psu.edu

Accepted for publication 7 November 2006.

doi:10.1094/PDIS-91-5-0517

(C) 2007 The American Phytopathological Society ous loss of turf in the northeast and midAtlantic region $(4,27)$. The disease also has been reported from the Midwest $(9,18,33)$, New England states (21), and western United States (28) in recent years. Outbreaks of gray leaf spot also have occurred on prg turf in golf courses in Japan (24). The disease first was reported in western Japan (Yamaguchi prefecture) in 1996. Subsequently, the disease spread to eastern Japan (Tochigi prefecture) in 1997, northern Japan (Akita prefecture) in 1998, and to at least six prefectures by 1999 (23).

Gray leaf spot of prg is caused by Magnaporthe oryzae Couch (3), anamorph Pyricularia oryzae Cavara (14) (formerly designated as Pyricularia grisea (Cooke) Sacc. (19) collectively), which infects more than 50 gramineous hosts. The fungus is known to exhibit a high degree of phenotypic and genotypic variability, and has been studied extensively $(17,34)$. Various molecular markers have been used to characterize the genetic structure of $M$. oryzae isolates $(3,6,8,14,25,30,32)$. The identification of several repetitive DNA sequences in the $M$. oryzae genome $(7,8,11)$ has facilitated population genetic analyses of isolates from rice and as well as other grasses. $M$. oryzae isolates from prg have an rDNA internal transcribed spacer sequence identical to that of isolates from wheat (Triticum aestivum L.), belong to a single mating type (MAT1-2) $(25,31)$, and consist of three closely related lineages (32). Additionally, Farman (6) has documented that prg isolates collected in the United States were very similar in fingerprint patterns to the MGR586, MAGGY, RETRO5, Pot2, and MGR583 probes, and were distinct from isolates from crabgrass, rice, and Setaria spp. Although the prg isolates are genetically similar to those from wheat, they are clearly distinct groups, suggesting that the isolates causing gray leaf spot of prg are host specific $(6,32)$. Recently, Tosa et al. (25) reported that the MGR586 fingerprints of Japanese prg isolates showed close similarity to the U.S. isolates. The prg isolates from Japan consisted of two distinct populations: one is highly virulent on and specific to prg, whereas the other is less virulent on prg but has some virulence on wheat.

Although genetic diversity among the isolates of $M$. oryzae causing gray leaf spot of prg in the United States and Japan has been investigated independently, the genetic relationships among the isolates from the two countries have not been extensively documented. Therefore, this study was undertaken to determine the genetic relationship between the prg isolates of $M$. oryzae from the United States and Japan.

\section{MATERIALS AND METHODS}

Collection and maintenance of isolates. Prg samples with gray leaf spot symptoms were collected from golf course fairways and roughs in Pennsylvania from 1995 to 2001. Symptomatic prg leaves were selected randomly from the samples, washed in tap water, placed on moist filter paper in petri dishes, and incubated for 24 to $48 \mathrm{~h}$ at $22^{\circ} \mathrm{C}$ to induce sporulation. Conidia were dislodged from individual sporulating lesions onto potato-dextroseagar (PDA) plates. Monoconidial isolates of $M$. oryzae were transferred to fresh PDA plates. For long-term storage, the isolates from the United States were preserved as previously described (29). Additionally, $M$. 
oryzae isolates from other states in the United States were obtained from Dr. Larry Stowell (Pace Turfgrass Research Institute, San Diego, CA), Dr. Andrew Hamblin (University of Illinois), Dr. Paul Vincelli (University of Kentucky), Dr. Gail Schumann (University of Massachusetts), Dr. Joseph Vargas (Michigan State University), Dr. Bruce Clarke (Rutgers, the State University of New Jersey), and Dr. Peter Dernoeden (University of Maryland). Isolates obtained from prg samples submitted to the turfgrass disease research laboratory at the Pennsylvania State University by Van Cortlandt Golf Course (Bronx, NY), Meadow Farms Golf Club (Locust Grove, VA), and Highland Springs Golf Course (Wellsburg, WV) also were included (Table 1). The isolates of $M$. oryzae from the United States also included an isolate from annual ryegrass collected by Dr. Larry Trevathan in 1972 (The American Type Culture Collection, accession number 64557). Isolates collected in Japan were obtained from Dr. A. Tanaka and Dr. T. Tani (Institute for Green Science, Japan) and were maintained at $4^{\circ} \mathrm{C}$ on barley seed. In this procedure, barley seeds with husks were soaked in $1 \%$ sucrose solution in test tubes ( 13 by $75 \mathrm{~mm}$ ) at room temperature for $24 \mathrm{~h}$. The excess sucrose solution was removed and the test tubes were capped with cotton plugs and sterilized for $20 \mathrm{~min}$. A 3-by-3-mm PDA block containing actively growing mycelia was placed in each test tube and incubated at room temperature for 7 to 10 days. When the seeds were colonized, they were transferred to a container with silica gel and stored at $4^{\circ} \mathrm{C}(10)$. In total, 58 monoconidial isolates from the United States and 24 from Japan were included in this study (Table 1).

DNA extraction. Individual isolates of $M$. oryzae were retrieved from storage, placed on full-strength PDA plates, and incubated at $28^{\circ} \mathrm{C}$ under 12-h (day and night) cycles of fluorescent light $\left(76 \mu \mathrm{E}^{-2}\right.$ $\mathrm{s}^{-1}$ ) for 7 to 10 days. Mycelial plugs were transferred to $50 \mathrm{ml}$ of 2 YEG broth (2 $\mathrm{g}$ of yeast extract and $10 \mathrm{~g}$ of glucose per liter), and incubated at $26^{\circ} \mathrm{C}$ for 3 days. The mycelial mats were harvested, freeze dried, and ground to a powder in liquid nitrogen using a mortar and pestle. The ground powder then was transferred to a micro- centrifuge tube containing $1 \mathrm{ml}$ of DNA isolation buffer $(100 \mathrm{mM} \mathrm{LiCl}, 100 \mathrm{mM}$ EDTA, $10 \mathrm{mM}$ Tris- $\mathrm{HCl}, \mathrm{pH} 7.5$, and $0.5 \%$ sodium dodecyl sulfate [SDS]) and mixed thoroughly by vortexing. After incubation at $55^{\circ} \mathrm{C}$ for $30 \mathrm{~min}$, the mycelial debris was precipitated by centrifugation at $10,000 \times$ $g$ for $10 \mathrm{~min}$. The supernatant was transferred to another tube and extracted twice with an equal volume of phenol:chloroform:isoamyl alcohol (25:24:1) and then once with an equal volume of chloroform:isoamyl alcohol (24:1). Genomic DNA was precipitated from the aqueous phase with isopropanol and recovered by centrifugation at $10,000 \times g$ for $15 \mathrm{~min}$. The DNA was washed with $1 \mathrm{ml}$ of $70 \%$ ethanol, dried in vacuum, and dissolved in $50 \mu \mathrm{l}$ of Tris-EDTA containing RNase (50 $\mu \mathrm{g} / \mathrm{ml}$ ) by incubating at room temperature overnight. The dissolved DNA sample was incubated at $37^{\circ} \mathrm{C}$ for $1 \mathrm{~h}$ and used for Southern analysis.

DNA fingerprinting. Southern hybridization was performed using the ECL Direct Nucleic Acid Labeling and Detection System (Amersham Biosciences, Buckinghamshire, UK). Probes used in this study

Table 1. Isolates of Magnaporthe oryzae from Lolium perenne and L. multiflorum from the United States and Japan used in the study

\begin{tabular}{|c|c|c|c|c|c|}
\hline M. oryzae isolate & Abbreviation & Host of origin & Location & Year of collection & Collector \\
\hline ATCC-64557 & U49 & L. multiflorum & Mississippi, United States & 1972 & L. Trevathan \\
\hline MD2-1 & U60 & L. perenne & Maryland, United States & 1995 & P. Dernoeden \\
\hline NJ1-2 & U66 & L. perenne & New Jersey, United States & 1995 & B. Clarke \\
\hline MD1-1 & U68 & L. perenne & Maryland, United States & 1995 & P. Dernoeden \\
\hline PgZen96-227-1 & U50 & L. perenne & Michigan, United States & 1996 & K. Gard \\
\hline PgZen96-227-2 & U51 & L. perenne & Michigan, United States & 1996 & K. Gard \\
\hline PgZen96-227-4 & U52 & L. perenne & Michigan, United States & 1996 & K. Gard \\
\hline WK3-1 & WK3-1 & L. perenne & Yamaguchi, Japan & 1996 & A. Tanaka and T. Tani \\
\hline WK3-2 & WK3-2 & L. perenne & Yamaguchi, Japan & 1996 & A. Tanaka and T. Tani \\
\hline WK4-1 & WK4-1 & L. perenne & Yamaguchi, Japan & 1996 & A. Tanaka and T. Tani \\
\hline WK4-2 & WK4-2 & L. perenne & Yamaguchi, Japan & 1996 & A. Tanaka and T. Tani \\
\hline WK4-3 & WK4-3 & L. perenne & Yamaguchi, Japan & 1996 & A. Tanaka and T. Tani \\
\hline WK4-4 & WK4-4 & L. perenne & Yamaguchi, Japan & 1996 & A. Tanaka and T. Tani \\
\hline TP-1 & TP-1 & L. perenne & Tochigii, Japan & 1997 & A. Tanaka and T. Tani \\
\hline TP-2 & TP-2 & L. perenne & Tochigii, Japan & 1997 & A. Tanaka and T. Tani \\
\hline TP-3 & TP-3 & L. perenne & Tochigii, Japan & 1997 & A. Tanaka and T. Tani \\
\hline TP-4 & TP-4 & L. perenne & Tochigii, Japan & 1997 & A. Tanaka and T. Tani \\
\hline TP-5 & TP-5 & L. perenne & Tochigii, Japan & 1997 & A. Tanaka and T. Tani \\
\hline ТP-6 & TP-6 & L. perenne & Tochigii, Japan & 1997 & A. Tanaka and T. Tani \\
\hline PgVA13M-06 & U61 & L. perenne & Virginia, United States & 1998 & W. Uddin \\
\hline PgWV17I-05 & U63 & L. perenne & West Virginia, United States & 1998 & W. Uddin \\
\hline PgPA05T-01 & U64 & L. perenne & Pennsylvania, United States & 1998 & W. Uddin \\
\hline PgPA18C-04 & U65 & L. perenne & Pennsylvania, United States & 1998 & W. Uddin \\
\hline PgNJ15C-03 & U67 & L. perenne & New Jersey, United States & 1998 & B. Clarke \\
\hline AK-1 & AK-1 & L. perenne & Akitai, Japan & 1998 & A. Tanaka and T. Tani \\
\hline AK-2 & AK-2 & L. perenne & Akitai, Japan & 1998 & A. Tanaka and T. Tani \\
\hline AK-3 & AK-3 & L. perenne & Akitai, Japan & 1998 & A. Tanaka and T. Tani \\
\hline AK-4 & AK-4 & L. perenne & Akitai, Japan & 1998 & A. Tanaka and T. Tani \\
\hline AK-5 & AK-5 & L. perenne & Akitai, Japan & 1998 & A. Tanaka and T. Tani \\
\hline FI-2 & FI-2 & L. perenne & Chiba, Japan & 1998 & A. Tanaka and T. Tani \\
\hline FI-3 & FI-3 & L. perenne & Chiba, Japan & 1998 & A. Tanaka and T. Tani \\
\hline FI-4 & FI-4 & L. perenne & Chiba, Japan & 1998 & A. Tanaka and T. Tani \\
\hline FI-5 & FI-5 & L. perenne & Chiba, Japan & 1998 & A. Tanaka and T. Tani \\
\hline PA02V18.1 & U1 & L. perenne & Pennsylvania, United States & 1999 & W. Uddin \\
\hline PA02V22.1 & $\mathrm{U} 2$ & L. perenne & Pennsylvania, United States & 1999 & W. Uddin \\
\hline PA02V26.2 & U3 & L. perenne & Pennsylvania, United States & 1999 & W. Uddin \\
\hline PgPA32H01.1 & $\mathrm{U} 4$ & L. perenne & Pennsylvania, United States & 1999 & W. Uddin \\
\hline PgPA32H03.1 & U5 & L. perenne & Pennsylvania, United States & 1999 & W. Uddin \\
\hline PgPA32H07.1 & U6 & L. perenne & Pennsylvania, United States & 1999 & W. Uddin \\
\hline PgPA33B.01 & U7 & L. perenne & Pennsylvania, United States & 1999 & W. Uddin \\
\hline \multirow[t]{2}{*}{ PgPA33B.03 } & U8 & L. perenne & Pennsylvania, United States & 1999 & W. Uddin \\
\hline & & & & & (continued on next page) \\
\hline
\end{tabular}


included MGR586 in pCB586 (8), Pot2 (11) in pPO-H (5), and MAGGY (7) in pMGY23 (26). These plasmids were maintained in Escherichia coli strain DH5 $\alpha$, extracted with QIAprep Spin Miniprep Kit (Qiagen, Hilden), and labeled following the manufacturer's instructions. Total DNA $(500 \mathrm{ng})$ from each of the isolates were digested with EcoRI and fractionated on a $0.8 \%$ agarose gel in $1 \times$ Tris-acetate-EDTA buffer. The fractionated DNA was transferred to a nylon membrane (Hybond- $\mathrm{N}^{+}$; Amersham Biosciences) with $20 \times$ SSC (1× $\mathrm{SSC}$ is $0.15 \mathrm{M} \mathrm{NaCl}$ plus $0.015 \mathrm{M}$ sodium citrate) and fixed by UV irradiation. The membrane was hybridized overnight with a labeled probe in Gold hybridization buffer (Amersham Biosciences) containing $0.5 \mathrm{M}$ $\mathrm{NaCl}$ at $42^{\circ} \mathrm{C}$. After hybridization, the membrane was washed twice in primary wash buffer (6 M urea, $0.4 \%$ SDS, $0.5 \times$ SSC) for $20 \mathrm{~min}$ at $42^{\circ} \mathrm{C}$, followed by two washes in $2 \times \mathrm{SSC}$ for $5 \mathrm{~min}$ at room temperature. Detection of target DNA was performed according to the manufacturer's instructions.

Construction of dendrograms. Bands were scored manually and represented as binary data with " 1 " for the presence of a band and "0" for absence. MGR586 bands were scored from the bottom of the gel up to $10 \mathrm{~kb}$, whereas Pot 2 bands were scored from the bottom of the gel up to $12 \mathrm{~kb}$. Genetic similarities were calculated using an neighbor-joining (NJ) program (20) and a maximum parsimony program in PAUP 4.0 (22). NJ trees were constructed from similarities calculated using Nei and Li's index of genetic similarity for restriction fragment length polymorphism comparisons (16). Maximum parsimony trees were constructed using the heuristic search option.

\section{RESULTS}

DNA fingerprinting with the MGR586 probe resulted in approximately 30 DNA fragments in 75 of the 82 isolates (Fig. 1A, represented by 13 isolates shown from the second to fourteenth lanes). All 75 isolates (designated major MGR586 group) exhibited highly similar fingerprint profiles. The remaining seven isolates (designated minor MGR586 group) had less than 15 bands (Fig. 1A, represented by two isolates shown at the first and last lanes). Among the $24 \mathrm{prg}$ isolates from Japan, both MGR586 groups were present. With the exception of an isolate (U68) collected in Maryland in 1995, all the U.S. isolates belonged to the major MGR586 group and exhibited high similarity to those in the major MGR586 group from Japan. The annual ryegrass isolate, $\mathrm{U} 49$, collected in Mississippi in 1972, also belonged to the major MGR586 group. To determine the genetic similarity among these isolates, the presence or absence of individual bands was converted into a binary ( 0 or 1$)$ matrix. Based on the resulting matrix, an unrooted tree was constructed using the $\mathrm{NJ}$ method, which then was rooted using the minor MGR586 group in Japan as an outgroup (Fig. 2A). The major MGR586 group in Japan was further divided into three subgroups (Fig. 2A). Isolates TP1, TP6, LW1, LW2, LW3, FI2, FI3, FI4, and FI5 collected from Tochigi, Yamanashi, and Chiba were identical, forming a subgroup (J1). Although TP5, an isolate from Tochigi, was slightly different from these isolates, it was close enough to be grouped with $\mathrm{J} 1$. The remaining isolates from Tochigi, TP2, TP3, and TP4, formed the second subgroup (J2), while all the isolates from Akita (AK1, AK2, AK3, AK4, and AK5) clustered together, forming the third

Table 1. (continued from preceding page)

\begin{tabular}{|c|c|c|c|c|c|}
\hline M. oryzae isolate & Abbreviation & Host of origin & Location & Year of collection & Collector \\
\hline PgPA33B.06 & U9 & L. perenne & Pennsylvania, United States & 1999 & W. Uddin \\
\hline PgIL9825-1 & U53 & L. perenne & Illinois, United States & 1999 & A. Hamblin \\
\hline PgIL9825-3 & U54 & L. perenne & Illinois, United States & 1999 & A. Hamblin \\
\hline PgIL9825-4 & U55 & L. perenne & Illinois, United States & 1999 & A. Hamblin \\
\hline LW-1 & LW-1 & L. perenne & Yamanashi, Japan & 1999 & A. Tanaka and T. Tani \\
\hline LW-2 & LW-2 & L. perenne & Yamanashi, Japan & 1999 & A. Tanaka and T. Tani \\
\hline LW-3 & LW-3 & L. perenne & Yamanashi, Japan & 1999 & A. Tanaka and T. Tani \\
\hline PgPA34M1.1 & U10 & L. perenne & Pennsylvania, United States & 2000 & W. Uddin \\
\hline PgPA34M1.2 & U11 & L. perenne & Pennsylvania, United States & 2000 & W. Uddin \\
\hline PgPA34M1.3 & U12 & L. perenne & Pennsylvania, United States & 2000 & W. Uddin \\
\hline PgPA35H1.1 & U13 & L. perenne & Pennsylvania, United States & 2000 & W. Uddin \\
\hline PgPA35H2.1 & U14 & L. perenne & Pennsylvania, United States & 2000 & W. Uddin \\
\hline PgPA35H4.1 & U15 & L. perenne & Pennsylvania, United States & 2000 & W. Uddin \\
\hline PgNJ36B.1.2 & U17 & L. perenne & New Jersey, United States & 2000 & B. Clarke \\
\hline PgPA08N7.1 & U19 & L. perenne & Pennsylvania, United States & 2000 & W. Uddin \\
\hline PgPA08N7.2 & $\mathrm{U} 20$ & L. perenne & Pennsylvania, United States & 2000 & W. Uddin \\
\hline PgPA08N7.3 & U21 & L. perenne & Pennsylvania, United States & 2000 & W. Uddin \\
\hline PgPA02V28.1 & U22 & L. perenne & Pennsylvania, United States & 2000 & W. Uddin \\
\hline PgPA02V 28.2 & $\mathrm{U} 23$ & L. perenne & Pennsylvania, United States & 2000 & W. Uddin \\
\hline PgMA37G1.1 & $\mathrm{U} 25$ & L. perenne & Massachusetts, United States & 2000 & G. Schumann \\
\hline PgMA37G2.1 & U26 & L. perenne & Massachusetts, United States & 2000 & G. Schumann \\
\hline PgMA37G2.3 & $\mathrm{U} 27$ & L. perenne & Massachusetts, United States & 2000 & G. Schumann \\
\hline PgPA39C 1.3 & $\mathrm{U} 28$ & L. perenne & Pennsylvania, United States & 2000 & W. Uddin \\
\hline PgPA39C2.1 & U29 & L. perenne & Pennsylvania, United States & 2000 & W. Uddin \\
\hline PgPA39C2.3 & U30 & L. perenne & Pennsylvania, United States & 2000 & W. Uddin \\
\hline PgPA09Lu6.1 & U31 & L. perenne & Pennsylvania, United States & 2000 & W. Uddin \\
\hline PgPA09Lu6.2 & U32 & L. perenne & Pennsylvania, United States & 2000 & W. Uddin \\
\hline PgPA09Lu6.3 & U33 & L. perenne & Pennsylvania, United States & 2000 & W. Uddin \\
\hline PgKY40V1.1 & U34 & L. perenne & Kentucky, United States & 2000 & P. Vincelli \\
\hline PgKY40V2.1 & U35 & L. perenne & Kentucky, United States & 2000 & P. Vincelli \\
\hline PgKY40V2.3 & U36 & L. perenne & Kentucky, United States & 2000 & P. Vincelli \\
\hline PgILLin & U56 & L. perenne & Illinois, United States & 2000 & A. Hamblin \\
\hline PgCA1.1.1 & U37 & L. perenne & California, United States & 2001 & L. Stowell \\
\hline PgCA1.2.3 & U38 & L. perenne & California, United States & 2001 & L. Stowell \\
\hline PgCA1.3.4 & U39 & L. perenne & California, United States & 2001 & L. Stowell \\
\hline PgPAWH1.1.1 & $\mathrm{U} 40$ & L. perenne & Pennsylvania, United States & 2001 & W. Uddin \\
\hline PgPAWH1.2.1 & U41 & L. perenne & Pennsylvania, United States & 2001 & W. Uddin \\
\hline PgPAWH2.2.2 & U42 & L. perenne & Pennsylvania, United States & 2001 & W. Uddin \\
\hline PgPALu1.1 & U43 & L. perenne & Pennsylvania, United States & 2001 & W. Uddin \\
\hline PgNYVC1.3.1 & U47 & L. perenne & New York, United States & 2001 & W. Uddin \\
\hline PgNYVC1.4.2 & U48 & L. perenne & New York, United States & 2001 & W. Uddin \\
\hline
\end{tabular}


subgroup (J3). Some of the isolates from the United States also belonged to these subgroups. For example, four U.S. isolates, U10, U11, U12, and U65, that were collected from Pennsylvania in 1998 and 2000, exhibited identical MGR586 fingerprints to most of the $\mathrm{J} 1$ isolates (Fig. 2A). An NJ dendrogram constructed using U68 (sole member of the minor MGR586 group in the United States) as an outgroup also showed a similar topology (data not shown).

Fingerprinting analysis of the $M$. oryzae isolates with the Pot2 probe produced similar groupings. All the isolates in the major MGR586 group showed very similar Pot 2 profiles, comprising 20 to 25 bands, within the group (Fig. 1B). In contrast, the isolates in the minor MGR586 group showed unique patterns with only a few bands. An NJ dendrogram, constructed from the Pot 2 data matrix using the minor MGR586 group in Japan as an outgroup, was very similar to that generated using the MGR586 data matrix (Fig. 2B). As with MGR586, the four isolates from the United States (U10, U11, U12, and U65) showed a Pot2 fingerprint identical to that of the J1 isolates from Japan (Fig. 2B). The NJ dendrogram constructed using the isolate U68 as an outgroup also showed a similar topology (data not shown).

When the MAGGY element was used as a probe, two distinct fingerprint types, type I (isolates exhibiting more than 30 bands) and type II (isolates with only 2 to 4 bands), were identified in the major MGR586 group (Fig. 1C). Both types were observed among the $M$. oryzae isolates from both countries. All the isolates belonging to the minor MGR586 group exhibited type II fingerprints. The functional copy of the MAGGY retrotransposon has five EcoRI sites and produces four internal EcoRI fragments of 0.6, 0.7, 1.0, and $1.2 \mathrm{~kb}$ (26). Isolates that showed the type I fingerprints had all four internal EcoRI fragments with strong hybridization signal (Fig. 1C), indicating that the five EcoRI sites are conserved in most of the MAGGY copies in these isolates. These type I isolates were closely associated with each other on the $\mathrm{NJ}$ dendrograms constructed from the MGR586 and Pot2 data (Fig. 2), irrespective of their geographical origin.

The MGR586 and Pot2 data were combined to produce integrated NJ and parsimony trees (Fig. 3A and 3B). The integrated NJ tree (Fig. 3A) was similar to the NJ tree based on the Pot2 data (Fig. 2B). Based on the topology of the parsimony tree, the isolates were divided into six lineages, A, B, C, D, E, and F (Fig. 3B). The major MGR586 group recognized in the NJ dendrograms (Figs. 2A and $\mathrm{B}$ and $3 \mathrm{~A}$ ) included lineages $\mathrm{A}, \mathrm{B}, \mathrm{C}$, and $\mathrm{D}$. Lineage $\mathrm{A}$, the largest group, was further divided into 10 subgroups, A1 through A10 (Fig. 3B). All the isolates that exhibited the MAGGY type I fingerprints belonged to the A9 subgroup regardless of their geographical origin. All Japanese isolates in the MGR586 major group belonged to either the A7 or A9 subgroup.

Lineage B, comprising two isolates from New York collected in 2001, was very closely related to lineage A (Fig. 3A). Lineage $\mathrm{C}$ consisted of a single isolate (U60) collected in Maryland in 1995. A single isolate, U49 (an annual ryegrass isolate), belonged to lineage D. Although lineage E consisted of the sole U.S. isolate in the MGR586 minor group, U68, lineage $F$ included the six Japanese isolates in the MGR586 minor group.
The geographic origins of the $M$. oryzae isolates analyzed in this study are shown in a chronological order with their lineage or subgroup names (Fig. 4). In 1995, the first year of the major gray leaf spot outbreak in the United States, isolates U68 (lineage E), U60 (lineage C), and U66 (subgroup A9 with the MAGGY type I) were collected. The subgroup A1, which currently is predominant in the United States, also was identified in the early years of the outbreak. Various subgroups in lineage A were observed in the United States in 1998. More diverse subgroups were identified in lineage A between 1999 and 2001, in which subgroup A1 was predominant. In Japan, a serious outbreak of gray leaf spot was caused by isolates that belonged to lineage F in 1996. Subsequently, in 1997 and 1998, subgroups A7 and A9 (both MAGGY type I and MAGGY type II) were identified (Fig. 4). All the isolates collected from 1999 to 2001 also belonged to the subgroup A7. These subgroups of the $M$. oryzae isolates also were found in the United States.

\section{DISCUSSION}

This is the first study that has documented the genetic relationships among the isolates of $M$. oryzae associated with gray leaf spot epidemics in the United States and Japan. In Japan, two distinct populations, differentiated by their MGR586 and Pot2 fingerprint patterns, exist among the prg isolates of M. oryzae (25). In the present study, we found that the major group prevailing in Japan is highly similar to the isolates that are prevailing in the United States Interestingly, the isolates from Japan that belonged to the A7 subgroup exhibited MGR586 or Pot fingerprints that were identical to certain
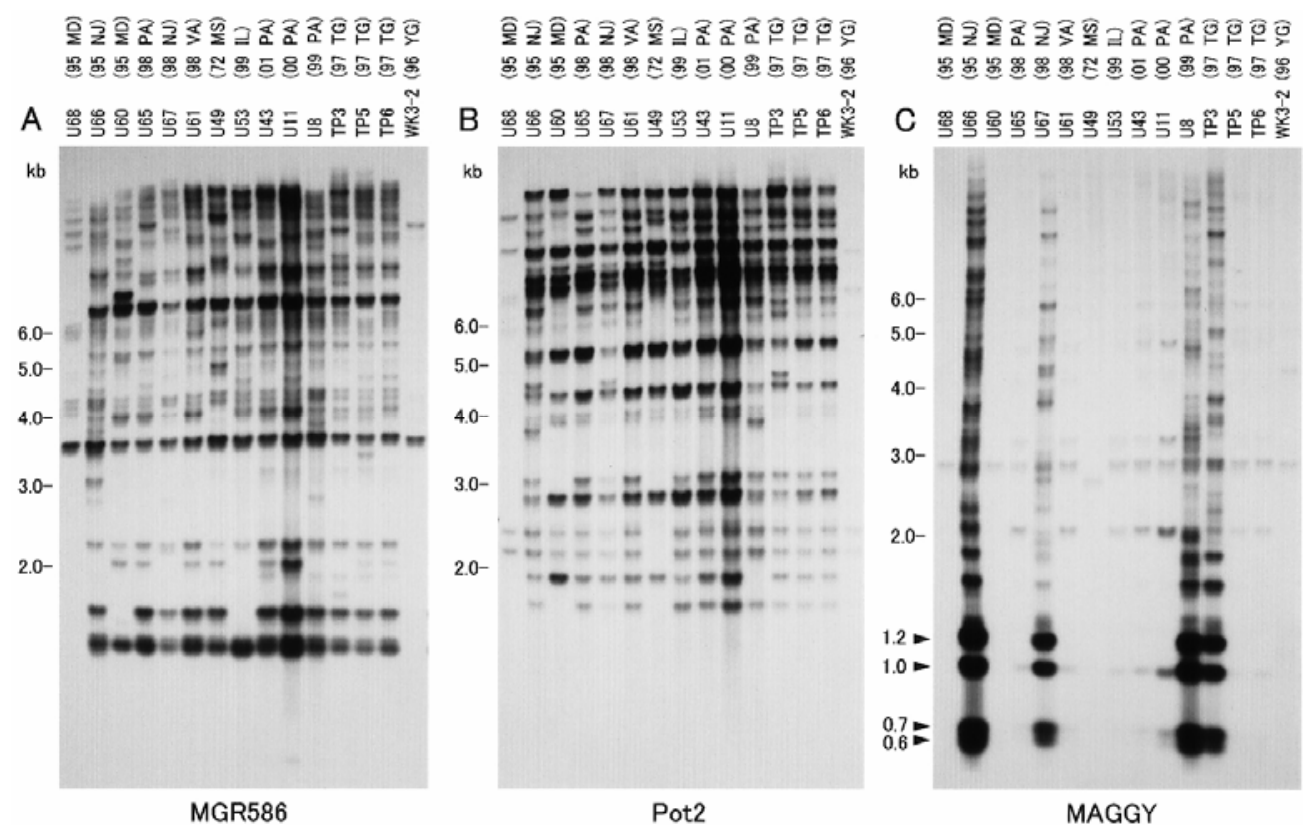

Fig. 1. Southern blot analysis of representative Magnaporthe oryzae isolates from the United States and Japan. Genomic DNA was digested with EcoRI, electrophoresed, and hybridized with A, MGR586, B, Pot2, and C, MAGGY. The arrows in C indicate internal fragments of the MAGGY retrotransposon. 


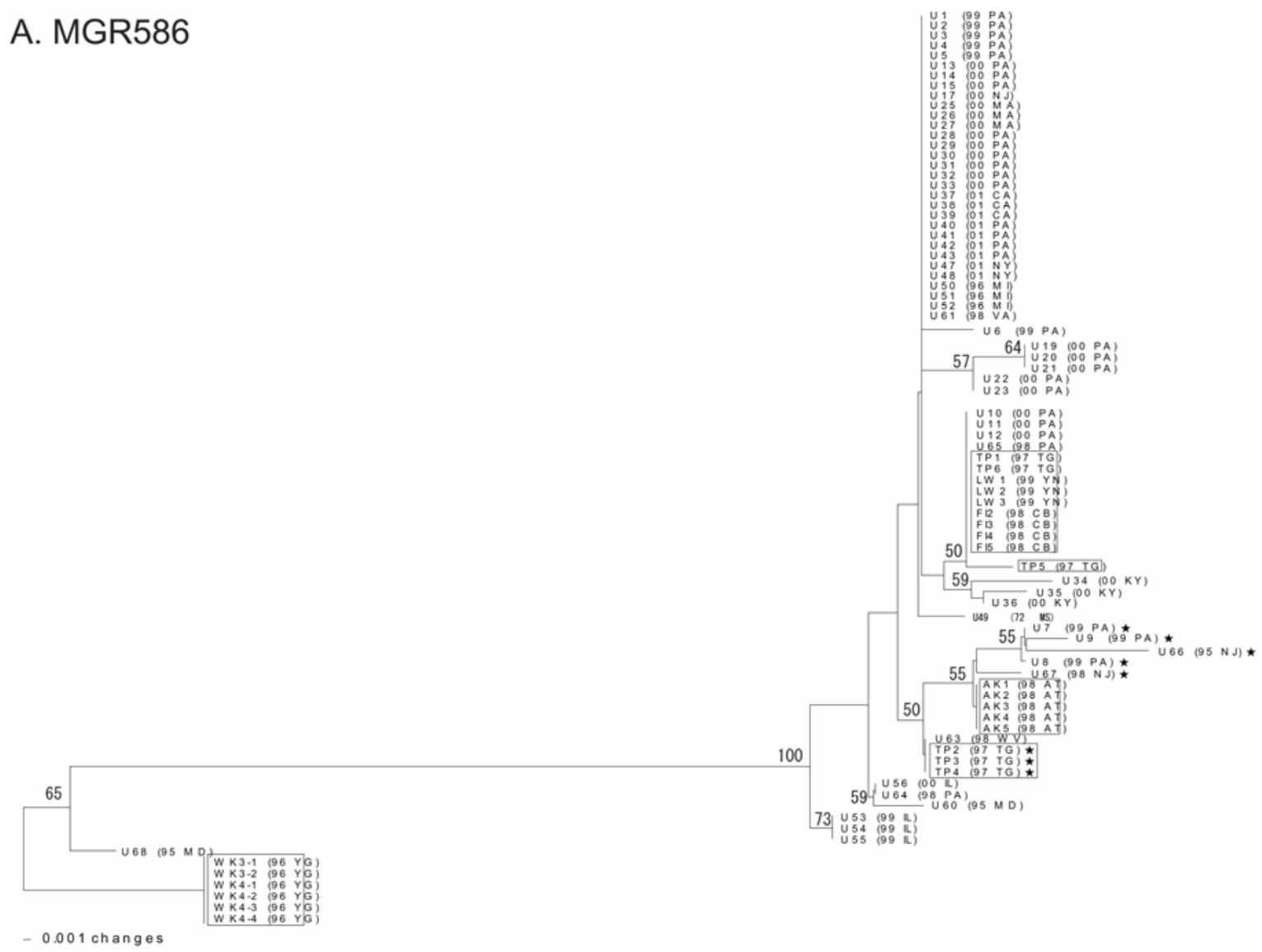

B. Pot2

Fig. 2. Neighbor-joining dendrograms of Magnaporthe oryzae isolates from the United States and Japan constructed from restriction fragment length polymorphism data using A, MGR586 and B, Pot2 probes. The Japanese isolates are enclosed in rectangles. The star symbols indicate isolates carrying approximately 30 copies of MAGGY (MAGGY type I). Numbers at nodes represent bootstrap support $>50 \%$ from 1,000 replications. 
A. NJ

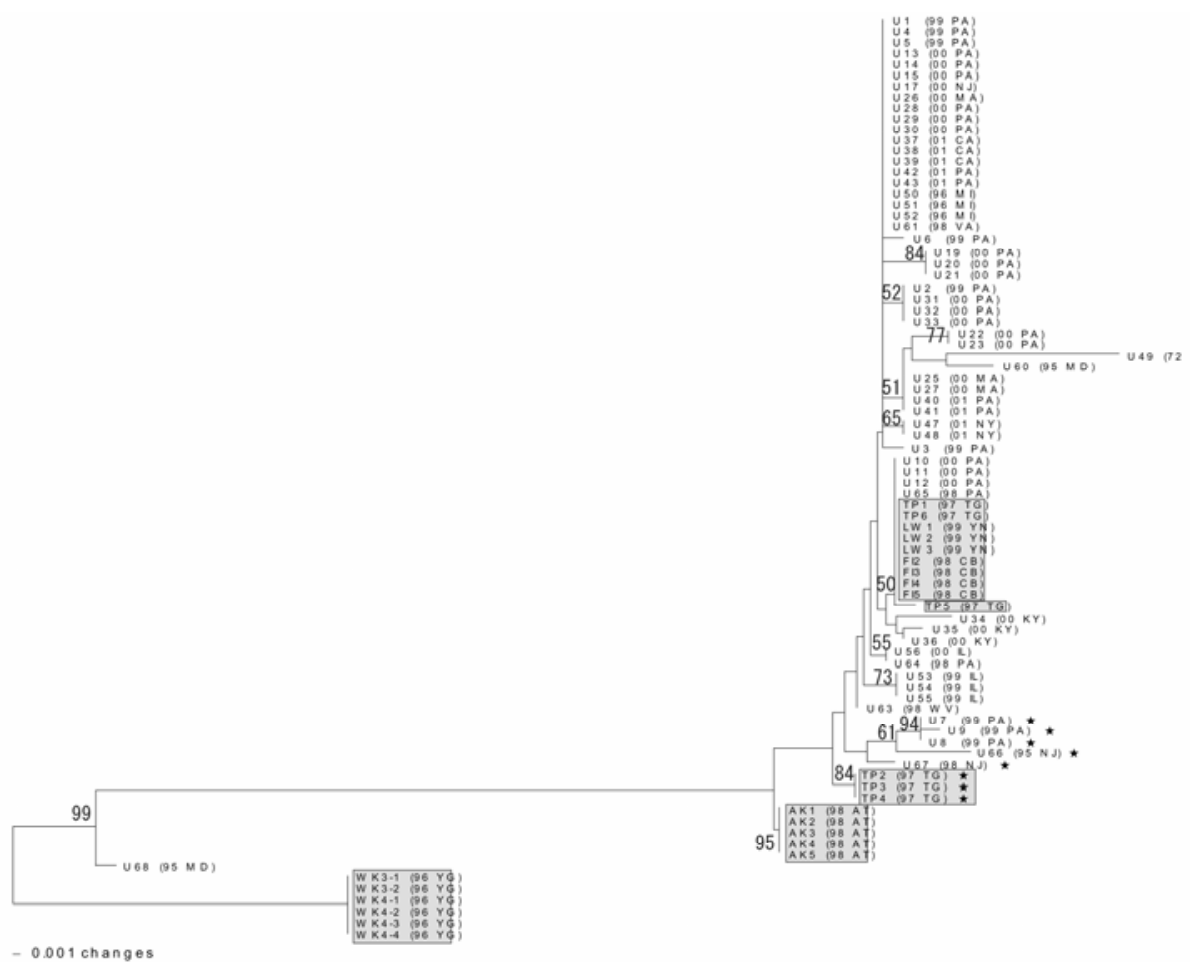

B. Parsimony

Fig. 3. Dendrograms of Magnaporthe oryzae isolates from the United States and Japan constructed from combined MGR586 and Pot2data. The Japanese isolates are enclosed in rectangles. The star symbols indicate isolates that belong to MAGGY type I. A, Neighbor-joining tree. Numbers at nodes represent bootstrap support $>50 \%$ from 1,000 replications. B, 50\% majority-rule consensus tree. The numbers on the tree represent percentages of parsimony trees possessing the branches. Tentative subgroup designation (A1 through $\mathrm{F}$ ) is shown on the right side. 
U.S. isolates (U10, U11, U12, and U65) from Pennsylvania (Fig. 3). Such close genetic similarity between the isolates from Pennsylvania and those Japanese isolates, and the relatively high genetic similarity among almost all the isolates from the United States and the majority of isolates from Japan, suggest that isolates of $M$. oryzae recently derived from a common ancestor might be responsible for the simultaneous outbreaks of gray leaf spot in Japan and the United States.

MAGGY is known to be the most active among the transposable elements that have been detected in M. oryzae thus far (5). A previous study (6) has shown that MAGGY fingerprints revealed the presence of three groups among prg isolates. The present study shows that the major group of prg isolates from the United States and Japan belong to two types (Fig. 1C). All the type $I$ isolates belonged to subgroup A9 (Fig. 3B). If the A9 subgroup is derived from an ancestor with multiple copies of MAGGY (i.e., type I isolate), all isolates in the A9 subgroup should carry multiple copies of MAGGY. However, the A9 subgroup included both type I and type II isolates of M. oryzae (Fig. 3B), suggesting that the ancestor of the A9 subgroup did not carry multiple copies of MAGGY but that MAGGY has multiplied in certain strains in the A9 subgroup. The long branches and diversities among the A9 isolates, as shown in the $\mathrm{NJ}$ dendrograms based on MGR586 and Pot2 fingerprint data (Fig. 2A and 2B), suggest that the MGR586 and Pot 2 transposons also could have been more active in this subgroup than other subgroups. It is possible that the ancestor of the A9 subgroup might have been defective in suppressing the multiplication of transposable elements.

A new group (lineage B) was detected among $M$. oryzae isolates collected during the epidemics from 1999 to 2001 in the United States Further, increased diversity with six additional subgroups (A2, A3, A4, A5, A6, and A8) was observed in lineage A during these years. It is noteworthy that one of the subgroups (A1) in the United States was found as far east as Massachusetts and as far west as California (Fig. 4). This subgroup appears to be predominant in the United States at present.

None of the isolates collected in the United States from 1995 to 2001, except one, showed fingerprint patterns similar to the Japanese isolates that belonged to the MGR586 minor group. Only one U.S. isolate (U68), collected from Maryland in 1995, was closely related to these Japanese isolates. The origin of the isolates in the MGR586 minor group is not clear. It is possible that these isolates might have been derived from indigenous $M$. oryzae isolates associated with non-turf gramineous hosts.

The results of this study suggest that isolates in the same lineage (lineage A) could have been involved in the simultaneous outbreaks of gray leaf spot in Japan and the United States. It is possible that strains of the pathogen were imported to different regions of the United States and Japan independently from an unidentified source. Alternatively, considering that Japanese companies have imported prg seed from the United States, they may have moved from the United States to Japan via seed trades. The widespread presence of a single lineage supports the possibility of seedborne transmission of the fungus. Studies have shown that the isolates of $M$. oryzae from rice are seed transmissible $(12,13)$. Further, the lack of genetic diversity among the host population also could be an important factor influencing population diversity of the pathogen. Studies on the genetic back-
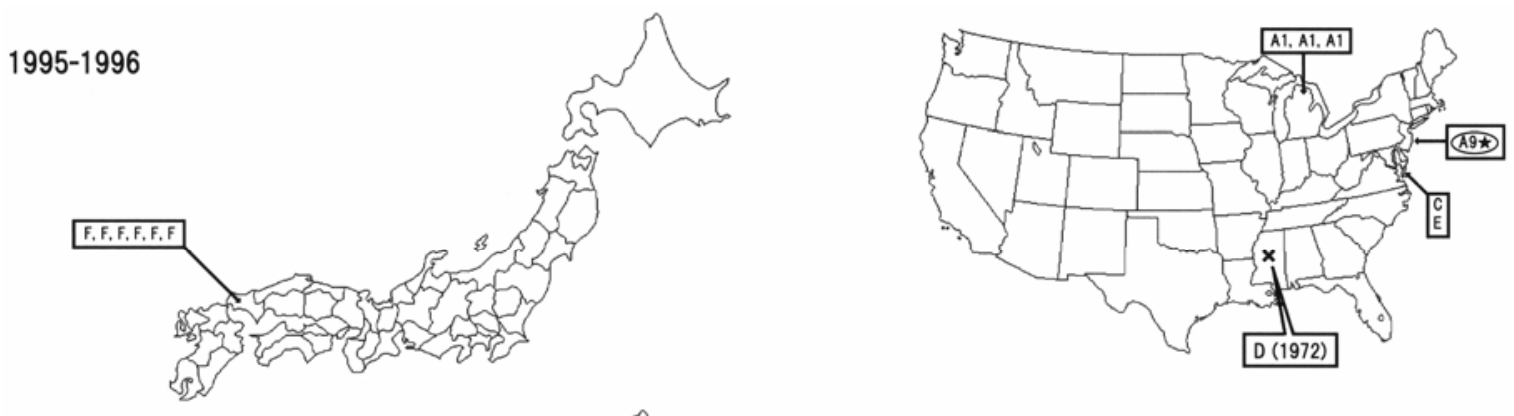

$1997-1998$
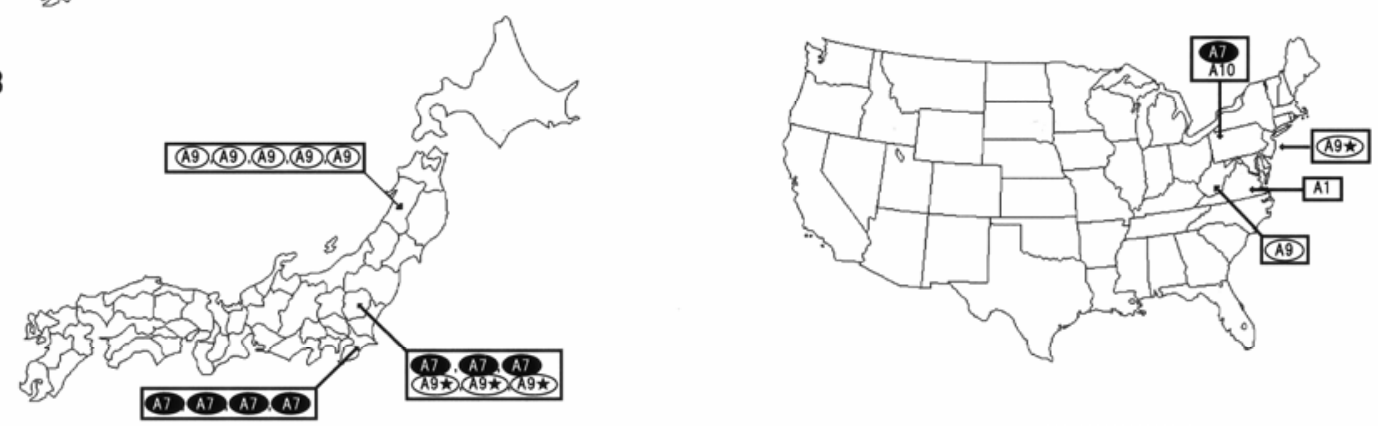

1999-2001
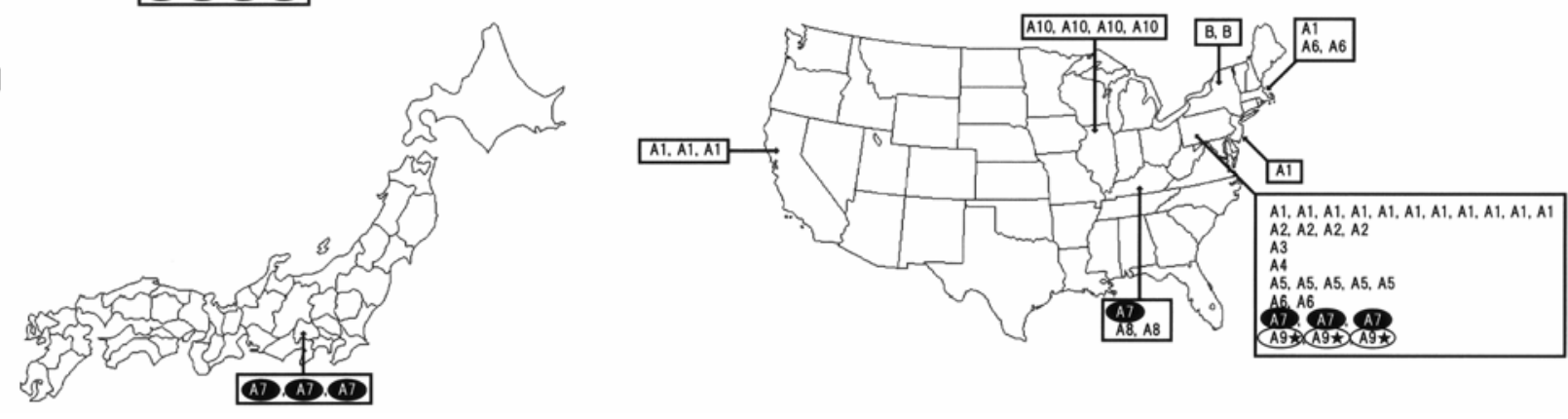

Fig. 4. Distribution patterns of Magnaporthe oryzae isolates associated with gray leaf spot epidemics on perennial ryegrass in the United States and Japan. Each isolate is plotted with its lineage or subgroup. A9 and A7, the two major subgroups prevailing in Japan, are marked with an oval and a black oval, respectively. The star symbols indicate isolates that belong to MAGGY type I. 
ground of prg cultivars grown in the United States and Japan and the role of seedborne transmission of the fungus are warranted.

\section{ACKNOWLEDGMENTS}

We thank B. Clarke, P. Dernoden, K. Gard, A. Hamblin, G. Schumann, L. Stowell, and P. Vincelli for providing isolates of $M$. oryzae used in this study; and G. Viji for significant contributions in preparation of the manuscript.

\section{LITERATURE CITED}

1. Bain, D. C., Patel, B. M., and Patel, M. V. 1972. Blast of ryegrass in Mississippi. Plant Dis. Rep. 56:210.

2. Carver, R. B., Rush, M., and Lindberg, G. D. 1972. An epiphytotic of ryegrass blast in Louisiana. Plant Dis. Rep. 56:157-159.

3. Couch, B. C., and Kohn, L. M. 2002. A multilocus gene genealogy concordant with host preference indicates segregation of a new species, Magnaporthe oryzae, from M. grisea. Mycologia 94:683-693.

4. Dernoeden, P. H. 1996. Perennial ryegrass and gray leaf spot. Golf Course Manage. 64:49-52.

5. Eto, Y., Ikeda, K., Chuma, I., Kataoka, T., Kuroda, S., Kikuchi, N., Don, L. D., Kusaba, M., Nakayashiki, H., Tosa, Y., and Mayama, S. 2001. Comparative analysis of the distribution of various transposable elements in Pyricularia and their activity during and after the sexual cycle. Mol. Gen. Genet. 264:565-577.

6. Farman, M. L. 2002. Pyricularia grisea isolates causing gray leaf spot on perennial ryegrass (Lolium perenne) in the United States: Relationship to $P$. grisea isolates from other host plants. Phytopathology 92:245-254.

7. Farman, M. L., Tosa, Y., Nitta, N., and Leong, S. A. 1996. MAGGY, a retrotransposon in the genome of the rice blast fungus Magnaporthe grisea. Mol. Gen. Genet. 251:665-674.

8. Hamer, J. E., Farrall, L., Orbach, M. J., Valent, B., and Chumley, F. G. 1989. Host speciesspecific conservation of a family of repeated DNA sequences in the genome of a fungal plant pathogen. Proc. Natl. Acad. Sci. USA 86:9981-9985

9. Harmon, P., Rane, K., Ruhl, G., and Latin, R. 2000. First report of gray leaf spot on perennial ryegrass in Indiana. Plant Dis. 84:492.

10. Hayashi, N., and Kato, H. 1988. Viability and aggressiveness of Pyricularia cultures preserved by silica gel-drying grain method. Proc. KantoTosan Plant Prot. Soc. 35:12-13. (In Japanese)
11. Kachroo, P., Leong, S. A., and Chattoo, B. B. 1994. Pot2, an inverted repeat transposon from the rice blast fungus Magnaporthe grisea. Mol. Gen. Genet. 245:339-348.

12. Kato, H. 1978. Biological and genetic aspects in the perfect state of rice blast fungus, Pyricularia oryzae Cav. and its allies. Gamma Field Symp. (Jpn.) 17:1-19.

13. Kato, H., Yamaguchi, T., and Nishihara, N. 1977. Seed transmission, pathogenicity and control of ragi blast fungus and susceptibility of ragi to Pyricularia spp. from grasses, cereals and mioga. Ann. Phytopathol. Soc. Jpn. 43:392-401. (In Japanese with English summary)

14. Kato, H., Yamamoto, M., Yamaguchi-Ozaki, T., Kadouchi, H., Iwamoto, Y., Nakayashiki, H., Tosa, Y., Mayama, S., and Mori, N. 2000. Pathogenicity, mating ability and DNA restriction fragment length polymorphisms of Pyricularia populations isolated from Gramineae, Bambusideae and Zingiberaceae plants. J. Gen. Plant Pathol. 66:30-47.

15. Landschoot, P. J., and Hoyland, B. F. 1992. Gray leaf spot of perennial ryegrass turf in Pennsylvania. Plant Dis. 76:1280-1282.

16. Nei, M., and Li, W. H. 1979. Mathematical model for studying genetic variation in terms of restriction endonucleases. Proc. Natl. Acad. Sci. USA 76:5269-5273.

17. Ou, S. H. 1980. Pathogen variability and host resistance in rice blast disease. Annu. Rev. Phytopathol. 18:167-187.

18. Pedersen, D. K., Kane, R. T., and Wilkinson, H. T. 2000. First report of gray leaf spot caused by Pyricularia grisea on Lolium perenne in Illinois. Plant Dis. 84:1151.

19. Rossman, A. Y., Howard, R. J., and Valent, B. 1990. Pyricularia grisea, the correct name for the rice blast fungus. Mycologia 82:509-512.

20. Saitou, N., and Nei, M. 1987. The neighborjoining method: a new method for reconstructing phylogenetic trees. Mol. Biol. Evol. 4:406425 .

21. Schumann, G. L., and Jackson, N. 1999. First report of gray leaf spot (Pyricularia grisea) on perennial ryegrass (Lolium perenne) in New England. Plant Dis. 83:1073.

22. Swofford, D. L. 1998. PAUP*. Phylogenetic Analysis Using Parsimony (*and Other Methods), Version 4. Sinauer Associates, Sunderland, MA.

23. Tanaka, A., Tamba, H., Tosa, Y., Mayama, S., and Tani, T. 2000. Gray leaf spot occurred on perennial ryegrass (Lolium perenne) in golf courses (2). (Abstr.) J. Jpn. Soc. Turf. Sci.
29:38-39. (In Japanese)

24. Tanaka, A., Urashima, A. S., Tosa, Y., Mayama, S., and Tani, T. 1998. Gray leaf spot occurred on perennial ryegrass (Lolium perenne) (Abstr.) J. Jpn. Soc. Turf. Sci. 27:116-117. (In Japanese)

25. Tosa, Y, Hirata, K., Tamba, H., Nakagawa, S. Chuma, I., Isobe, C., Osue, J., Urashima, A. S. Don, L. D., Kusaba, M., Nakayashiki, H., Tanaka, A., Tani, T., Mori, N., and Mayama, S. 2004. Genetic constitution and pathogenicity of Lolium isolates of Magnaporthe oryzae in comparison with host species-specific pathotypes of the blast fungus. Phytopathology 94:454-462.

26. Tosa, Y., Nakayashiki, H., Hyodo, H., Mayama, S., Kato, H., and Leong, S. A. 1995. Distribution of retrotransposon MAGGY in Pyricularia species. Ann. Phytopathol. Soc. Jpn. 61:549-554.

27. Uddin, W., Soika, M. D., Moorman, F. E., and Viji, G. 1999. A serious outbreak of blast disease (gray leaf spot) of perennial ryegrass in golf course fairways in Pennsylvania. Plant Dis. 83:783.

28. Uddin, W., Viji, G., and Stowell, L. 2002. First report of gray leaf spot of perennial ryegrass in sports field in California. Plant Dis. 86:75.

29. Valent, B., Farrall, L., and Chumley, F. G. 1986. Genetic studies of fertility and pathogenicity in Magnaporthe grisea (Pyricularia oryzae). Iowa State Univ. Res. 60:569-594.

30. Viji, G., Gnanamanickam, S. S., and Levy, M. 2000. DNA polymorphisms of isolates of Magnaporthe grisea from India that are pathogenic to finger millet and to rice. Mycol. Res. 104:161-167.

31. Viji, G., and Uddin, W. 2002. Distribution of mating type alleles and fertility status of Magnaporthe grisea causing gray leaf spot of perennial ryegrass and St. Augustinegrass turf. Plant Dis. 86: 827-832.

32. Viji, G., Wu, B., Kang, S., Uddin, W., and Huff, D. R. 2001. Pyricularia grisea causing gray leaf spot of perennial ryegrass turf: population structure and host specificity. Plant Dis. 85:817-826

33. Vincelli, P., and Dixon, E. 2002. Resistance to $\mathrm{Q}_{\mathrm{o}} \mathrm{I}$ (Strobilurin-like) fungicide in isolates of Pyricularia grisea from perennial ryegrass. Plant Dis. 86:235-240.

34. Zeigler, R. S., Cuoc, L. X., Scott, R. P., Bernardo, M. A., Chen, D. H., Valent, B., and Nelson, R. J. 1995. The relationship between lineage and virulence in Pyricularia grisea in the Philippines. Phytopathology 85:443-451. 